$\mathrm{AB} 0365$

EFFICACY OF TOCILIZUMAB FOR CORTICOSTEROID AND METHOTREXATE SPARING IN RHEUMATOID ARTHRITIS

Panagiotis Athanassiou ${ }^{1}$, Marina Gatsiou', Lambros Athanassiou ${ }^{2}$, Pavlos Tsakiridis ${ }^{1}$, Aikaterini Tzanavari ${ }^{1}$, Eirini Devetzi ${ }^{1}$, Charoula Katsavouni ${ }^{1}$, Ifigenia Kostoglou-Athanassiou ${ }^{3}$ ' $^{1}$ St. Paul's Hospital, Department of Rheumatology, Thessaloniki, Greece, ${ }^{2}$ Asclepeion Hospital, Voula, First Department of Internal Medicine, Thessaloniki, Greece; ${ }^{3}$ Asclepeion Hospital, Voula, Department of Endocrinology, Athens, Greece

Background: Successful management of rheumatoid arthritis (RA) depends on the early administration of DMARDs and biologic DMARDs. The biologic agent tocilizumab, an interleukin-6 receptor inhibitor, has been used for the management of RA.

Objectives: The aim was to describe a cohort of RA patients treated with tocilizumab and the effect of this treatment on the other DMARDs used, namely methotrexate and corticosteroids.

Methods: In a cohort of 80 patients with rheumatoid arthritis the biologic agent tocilizumab was administered in combination with methotrexate administered sc and $10 \mathrm{mg}$ prednisolone. Within this cohort, 26 patients were on tocilizumab administered iv $8 \mathrm{mg} / \mathrm{kg} / 4 \mathrm{wks}$ (maximum dose 800 $\mathrm{mg}$ ) and 54 were on tocilizumab administered sc $162 \mathrm{mg} / \mathrm{wk}$. As corticosteroid administration is characterized by adverse effects, such as osteoporosis and diabetes mellitus, in the course of the disease, in all patients an effort was made to reduce and, if possible, withdraw corticosteroids. An effort was also made to reduce methotrexate dosage. After a year, prednisolone was either significantly reduced or withdrawn. The final dosage of prednisolone was either $2.5-5 \mathrm{mg}$ or complete withdrawal. The successful reduction of methotrexate dosing schedule was also achieved. The final methotrexate dose was either $12.5 \mathrm{mg} \mathrm{sc}$ or complete withdrawal. After a period of 52 weeks in this cohort 42 of 80 patients $(52.5 \%)$ were on monotherapy with tocilizumab.

Results: In a cohort of 80 patients with RA the administrations of tocilizumab, either iv or Sc, proved safe and effective. Remission or low disease activity of RA was achieved. Corticosteroid dosage was reduced. Methotrexate dosage was also reduced. After 52 weeks within the group of RA patients on treatment with tocilizumab, in 42 complete withdrawal of corticosteroids and methotrexate proved feasible. Patients on tocilizumab monotherapy remained in remission.

Conclusion: It appears that tocilizumab is safe and effective for the treatment of RA. Tocilizumab treatment may permit withdrawal of both corticosteroids and methotrexate in patients with RA. The management of active RA initially with low dose corticosteroids in combination with methotrexate sc and, in the case of failure to achieve remission, with the addition of the biologic agent tocilizumab had as a result either significant corticosteroid reduction or complete withdrawal and reduction of methotrexate dosage, the disease remaining in remission.

Disclosure of Interests: None declared

DOI: 10.1136/annrheumdis-2019-eular.8171

\section{AB0366 COMPARISON OF THE EFFECT OF RITUXIMAB (ROCHE) AND RITUXIMAB BIOSIMILAR - BCD-020 (BIOCAD) ON INFLAMMATORY AND IMMUNOLOGICAL BIOMARKERS IN PATIENTS WITH RHEUMATOID ARTHRITIS}

Anastasia Avdeeva ${ }^{1}$, Maria Cherkasova ${ }^{1}$, Alexander Artyuhov $^{2}$, Eh. Dashinimaev ${ }^{2}$, D. Kusevich ${ }^{3}$, Alexander Lila ${ }^{1}$, Evgeny Nasonov ${ }^{1} .{ }^{1} V$. A. Nasonova Research Institute of Rheumatology, Moscow, Russian Federation; ${ }^{2}$ Pirogov Russian National Research Medical University, Moscow, Russian Federation; ${ }^{3}$ V.A. Nasonova Research Institute of Rheumatology, Sechenov University, Moscow, Russian Federation

Background: BCD-020 (BIOCAD) is the first Russian rituximab (RTX) biosimilar which was approved for medical use in rheumatoid arthritis (RA) patients in Russia and some CIS countries

Objectives: To evaluate the changes in acute phase reactants, autoantibodies, immunoglobulins, cytokine profile and CD19+B lymphocytes in patients (pts) with RA during RTX and RTX biosimilar therapy

Methods: The study included 54 RA patients (pts), divided into two groups. The first group included 34 pts with RA (31 women, mean age 49(42-64), mean disease duration 66(36-132) months, mean DAS 286.2 (5.5-6.8)) who received two infusions of RTX - 35\% at a dose of 500 $\mathrm{mg}, 65 \%$ of the dose of $1000 \mathrm{mg}$ every two weeks in combination with DMARDs and glucocorticoids; 33 pts achieved a good/moderate EULAR response at week 24. The second group - 20 pts with RA (18 woman, mean age 61.5(54-66.5) years, mean disease duration 39.5(20-84) months, mean DAS 28 5.6(4.9-6.8)) who received two intravenous BCD-
020 infusions (600mg No 2) in combination with DMARDs and glucocorticoids; 17 pts achieved a good/moderate EULAR response at week 24 Laboratory biomarkers were assessed at baseline and weeks 12 and 24 after the first infusion of RTX. ESR (mm/hr) (Westergren method); serum concentrations of CRP (mg/L), IgM RF (IU/ml) (laser nephelometry); antiCCP2 $(\mathrm{U} / \mathrm{ml})$, IgA RF $(\mathrm{U} / \mathrm{ml})$, anti-MCV $(\mathrm{U} / \mathrm{ml})$ (ELISA kits); cytokine profile (xMAP technology) were assessed

Results: RTX and BCD-020 induced decreases in ESR, levels of CRP, IgMRF, IgARF, anti-MCV at week 12 and 24, p<0.05 (tabl.1). At week $24-20 \%$ of IgMRF positive pts at baseline (in the first group) and $10 \%$ of IgMRF positive pts (in the second group) turned negative. Levels of anti-CCP2 did not reduced. At week $24-7 \%$ of anti-CCP2 positive pts at baseline (in the first group) and $15 \%$ of anti-CCP2 positive pts (in the second group) turned negative. Depletion of CD19+B-cells was achieved at week 12 in all patients (absolute number 0 ), with an increase in the level of B cells at week 24, tabl.1. The immunoglobulin level decreased at week 24, but remained normal. In the first group RTX induced reduction in proinflammatory (IL-1b, IL-2, IL-6, IL-12, IL-15, IFN- $\gamma$, TNF- $\alpha$ ), antiinflammatory cytokines (IL-1Ra, IL-5, IL-9, IL-10, IL-13), growth factors (IL7, GM-CSF, FGF-basic) and chemokines (MC-1) at week 24 (fig.1). In the second group BCD-020 induced reduction in IL-1b, IL-1Ra, IL-2, IL-4 IL-5, IL-6, IL-7, IL-8, IL-9, IL-10, IL-12, IL-13, IL-15, IL-17, Eotaxin, GCSF, IFN- $\gamma$, IP-10, MC-1, MIP-1 $\beta$, TNF- $\alpha$, VEGF at week $24 \quad p<0.05$, fig.1.
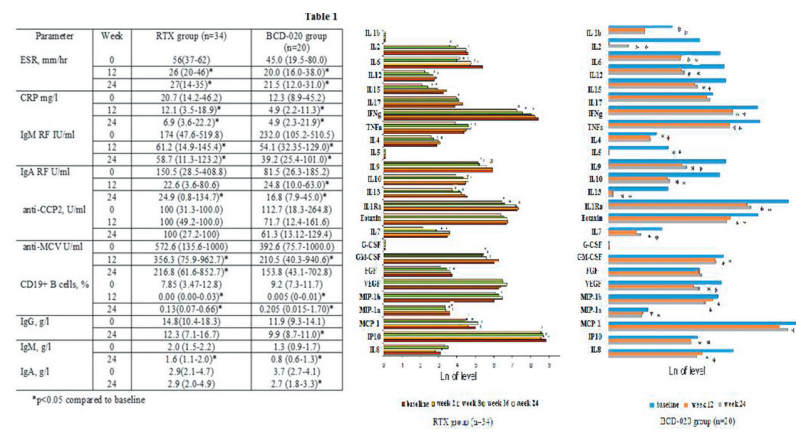

Figure 1

Conclusion: RTM biosimilar (BCD-020) has a similar effect on inflammatory and immunological biomarkers to the original RTM. BCD-020 therapy induced a rapid and significant improvement in ESR, levels of CRP, IgM IgARF, anti-MCV, proinflammatory, anti-inflammatory cytokines, growth fac tors, chemokines levels and CD19+B cells depletion in RA pts

Disclosure of Interests: Anastasia Avdeeva: None declared, Maria Cherkasova: None declared, Alexander Artyuhov: None declared, Eh. Dashinimaev: None declared, D. Kusevich: None declared, Alexander Lila Speakers bureau: Pfizer, Inc., MSD, Novartis, AbbVie Inc., Celgen Corporation, Biocad, Janssen, UCB, Inc., Evgeny Nasonov: None declared DOI: 10.1136/annrheumdis-2019-eular.2748

\section{AB0367 REASONS FOR DISCONTINUATION OF BIOLOGICAL DRUG AND TARGETED SYNTHETIC DRUGS AMONG PATIENTS WITH INFLAMMATORY ARTHRITIS IN THE UNITED ARAB EMIRATES (UAE)}

Humeira Badsha ${ }^{1}$, Ghita Harifi ${ }^{1}$, Richard Kirubakaran ${ }^{2}$, Bhavna Khan ${ }^{3} .{ }^{1} D r$ Humeira Badsha Medical Center - Rheumatology and Arthritis, Dubai, United Arab Emirates; ${ }^{2}$ Cochrane South Asia, Vellore, India; ${ }^{3}$ Integrated Arthritis and Rheumatology Centre, Dubaoi, United Arab Emirates

Background: In routine clinical care of Rheumatoid arthritis (RA) Spondyloarthritis(SPA) and Psoriatic arthritis (PSA) there is a high rate of discontinuation of biologic disease-modifying antirheumatic drugs (bDMARDs) and targeted synthetic disease-modifying antirheumatic drugs (tsDMARDs) due to loss of efficacy, side effects or lack of adherence. This can impact on the ability to achieve low disease activity.

Objectives: To evaluate the use of bDMARDs and tsDMARds and analyze the reasons for discontinuation of these drugs and to compare them to our standard DMARD Methotrexate.

Methods: In this retrospective cohort analysis we included consecutive patients aged $\geq 18$ years with RA/SPA/PSA attending 2 Rheumatology clinics in the UAE from August- December 2019. Statistical analysis was performed using STATA version 13 and R-studio. Continuous data were 
summaries as mean and SD. Dichotomous data were presented as percentage. Chi square test, Proportion test and T-test were applied based on the data type and its distribution to calculated P-value at a $5 \%$ level of significance

Results: Of 745 patients who were included, 453 (60.8\%) had RA,165 $(22.5 \%)$ SPA, and $127(16.7 \%)$ PSA. Of these a total of $353(47.3 \%)$ received 565 treatment courses with bDMARDs and 106patients had $(14.2 \%)$ had110 treatment courses with tsDMARD, and $480(64.4 \%)$ Methotrexate(MTX)

$100 / 353(28.3 \%)$ of patients discontinued bDMARds; $35 / 106(33.0 \%$ ) of patients discontinued tsDMARds; and 254/480(52.9\%) MTX. 52\% of treatment courses of bDMARD andd $36 \%$ courses of tsDMARD were discontinued. Reasons for discontinuation are in table 1.

Factors such as age, gender,ethinicity were not significantly associated with the rate of discontinuation of medications (Chi-square test). 647/745 $(86.6 \%)$ of patients had medical insurance, however lack of insurance did not lead to discontinuation of bDMARDs (OR=0.54 95\% Cl $(0.22$ to 1.32)) and tsDMARDs (OR= $1.5995 \% \mathrm{Cl}:(0.3-8.3))$. A significant proportion of patients $(15 \%-18 \%)$ in all the three groups have stopped the drugs of their own choice. We did not observe any statistical significant difference between the active and discontinued categories with respect to disease activity scores das 28 for RA; BASDAI for SPA and HAQ score for PSA.

Table 1. Distribution of different medications

\begin{tabular}{lccccccc}
\hline Number of patients & \multicolumn{2}{c}{$\begin{array}{c}\text { bDMARDS } \\
(\mathrm{n}=353)\end{array}$} & \multicolumn{2}{c}{$\begin{array}{c}\text { tsDMARDS } \\
(\mathrm{n}=106)\end{array}$} & $\begin{array}{l}\text { Methotrexate } \\
(\mathrm{n}=480)\end{array}$ & P value \\
\hline Actively on Rx & 253 & $72 \%$ & 71 & $67 \%$ & 226 & $47 \%$ & $<0.001^{*}$ \\
Discontinuation & 100 & $28 \%$ & 35 & $33 \%$ & 254 & $53 \%$ & \\
Total & 353 & $100 \%$ & 106 & $100 \%$ & 480 & $100 \%$ & \\
Reasons for Discontinuation & & & & & & \\
Unknown reason & 8 & $8 \%$ & 4 & $11 \%$ & 18 & $7 \%$ & 0.66 \\
Side effect & 8 & $8 \%$ & 4 & $11 \%$ & 92 & $36 \%$ & $<0.001^{*}$ \\
Primary loss of & 10 & $10 \%$ & 9 & $26 \%$ & 18 & $7 \%$ & $0.001^{*}$ \\
efficacy & & & & & & & \\
Secondary loss of & 27 & $27 \%$ & 10 & $29 \%$ & 46 & $18 \%$ & 0.101 \\
efficacy & & & & & & & \\
Doctors choice & 7 & $7 \%$ & 1 & $3 \%$ & 11 & $4 \%$ & 0.486 \\
Patient choice & 17 & $17 \%$ & 1 & $3 \%$ & 37 & $15 \%$ & 0.118 \\
Pregnancy & 5 & $5 \%$ & 0 & $0 \%$ & 24 & $9 \%$ & 0.075 \\
Remission & 10 & $10 \%$ & 3 & $9 \%$ & 8 & $3 \%$ & $0.025^{*}$ \\
Financial & 6 & $6 \%$ & 3 & $9 \%$ & 0 & $0 \%$ & $<0.001^{*}$ \\
Infection & 2 & $2 \%$ & 0 & $0 \%$ & 0 & $0 \%$ & $0.001^{*}$ \\
Total & 100 & $100 \%$ & 35 & $100 \%$ & 254 & $100 \%$ & \\
\hline & & & & & & &
\end{tabular}

$P$ value is computed using proportion test

* statistical significance difference at 5\%

Conclusion: A significantly higher proportion of patients discontinued MTX as compared to bDMARDs and tsDMARDs. Major reason for stopping MTX was side effects while bDMARDs and TsDMARDS were mainly stopped due to loss of efficacy or financial reasons. Safety and tolerability of bDMARDs and tsDMARDs was good in our cohort of patients.

\section{REFERENCES}

[1] Ebina K,et al. Drug retention and discontinuation reasons between seven biologics in patients with rheumatoid arthritis -The ANSWER cohort study. PLoS One. 2018 Mar 15;13(3)

[2] Favalli EG, et al. Real-life 10-year retention rate of first-line anti-TNF drugs for inflammatory arthritides in adult- andjuvenile-onset populations: similarities and differences. ClinRheumatol. 2017Aug;36(8):1747-1755.

Disclosure of Interests: None declared

DOI: 10.1136/annrheumdis-2019-eular.7570

\section{AB0368 2 SAFETY OF COMBINATION THERAPY WITH TWO BIOLOGIC DISEASE-MODIFYING ANTI-RHEUMATIC DRUGS IN PATIENTS WITH RHEUMATOID ARTHRITIS: A SYSTEMATIC REVIEW AND META-ANALYSIS}

Gonçalo Boleto $^{1,2}$, Lukshe Kanagaratnam ${ }^{3}$, Moustapha Dramé ${ }^{3}$, JeanHugues Salmon". 'Maison Blanche Hospital, Reims University Hospitals, Rheumatology Department, Reims, France; ${ }^{2}$ Hopital La Pitié Salpêtrière, Department of Internal Medicine and Clinical Immunology, Paris, France; ${ }^{3}$ Robert Debré Hospital, Reims University Hospitals, Department of Research and Innovation, Reims, France

Background: About $20 \%$ to $40 \%$ of patients with rheumatoid arthritis (RA) treated with biologic therapies fail to achieve remission consequently requiring additional treatment (1-4). Combining different biologic agents could be a promising therapeutic strategy. However, the safety and tolerability of combining different biologic agents is one of the major concerns of this treatment approach.

Objectives: We performed a systematic review and meta-analysis of the current literature to assess the safety of combining two bDMARDs (biologic disease-modifying anti-rheumatic drugs) in the treatment of patients with RA.

Methods: We searched PubMed, the Cochrane Library, Scopus, ClinicalTrials.gov, and the WHO International Clinical Trials Registry platform through 12/18/17. Our eligibility criteria included human RCTs or observational or non-randomized comparative studies in adults $(\geq 18$ years of age) that recorded safety of combination therapy with two bDMARDs in RA patients. We used $R$ version 3.1 .2 to perform meta-analysis between groups on combination therapy and placebo/single therapy alone using random effect model calculating odds ratio $(\mathrm{OR})$ as well as $95 \%$ confidence interval $(\mathrm{Cl})$. Cochran $\mathrm{Q}$ statistic and $\mathrm{I}^{2}$ statistic was used to identify heterogeneity between studies. The primary outcome was the rate of major serious events. Additional outcomes were the rate of total adverse events, total infectious events and major infectious events.

Results: Six studies with a total of 623 patients (410 on combination therapy and 213 on single therapy) were included for meta-analysis Median follow-up was 9.5 months (range 6-12 months). There was a significant increase in SAEs in the combination group (14.9 vs $6.0 \%$, OR $2.51,95 \% \mathrm{Cl} 1.29-4.89, \mathrm{I}^{2} 0 \%$ ) as well as in total adverse events (94.6 vs $89.1 \%$, OR $2.07,95 \% \mathrm{Cl} 1.11-3.86, \mathrm{I}^{2} 0 \%$ ). When performing subgroup analysis in patients receiving only full-dose of both bDMARDs there was a significant increase in serious infections (6.7 vs $0.6 \%$, OR $5.58,95 \%$ Cl $1.25-24.90, \mathrm{I}^{2} 0 \%$ ) and the risk of SAEs remained significantly higher (17.1 vs $6.2 \%$, OR $2.72,95 \% \mathrm{Cl} 1.30-5.69, \mathrm{I}^{2} 0 \%$ ).

Conclusion: Our findings suggest that combination therapy with two bDMARDs in RA patients appears to increase the risk of SAEs during the first twelve months of treatment.

\section{REFERENCES}

[1] -Lipsky PE, et al. Infliximab and methotrexate in the treatment of rheumatoid arthritis. Anti-Tumor Necrosis Factor Trial in Rheumatoid Arthritis with Concomitant Therapy Study Group. N Engl J Med. 2000 Nov 30;343 (22):1594-602

[2] Weinblatt ME, et al. Adalimumab, a fully human anti-tumor necrosis factor alpha monoclonal antibody, for the treatment of rheumatoid arthritis in patients taking concomitant methotrexate: the ARMADA trial. Arthritis Rheum. 2003 Jan;48(1):35-45.

[3] Keystone ECet al. Once-weekly administration of $50 \mathrm{mg}$ etanercept in patients with active rheumatoid arthritis: results of a multicenter, random ized, double-blind, placebo-controlled trial. Arthritis Rheum. 2004 Feb;50 (2):353-63.

[4] Weinblatt ME, et al. A trial of etanercept, a recombinant tumor necrosis factor receptor:Fc fusion protein, in patients with rheumatoid arthritis receiving methotrexate. N Engl J Med. 1999 Jan 28;340(4):253-9.

Disclosure of Interests: Gonçalo Boleto: None declared, Lukshe Kanagaratnam: None declared, Moustapha Dramé: None declared, Jean-Hugues Salmon Speakers bureau: Janssen Novartis

DOI: 10.1136/annrheumdis-2019-eular.307

\section{AB0369 1 SAFETY, EFFICACY AND RETENTION RATE OF BIOLOGIC DISEASE MODIFYING ANTI-RHEUMATIC DRUGS (BDMARDS) IN ASSOCIATION WITH DENOSUMAB: COMPARISON OF COMBINATION AND MONO-THERAPY REGIMENS}

Cosimo Bruni, Cosimo Cigolini, Giulia Tesei, Francesca Bartoli, Ginevra Fiori, Maria Letizia Conforti, Silvia Bellando Randone, Serena Guiducci, Marco MatucciCerinic. Careggi University Hospital, Firenze, Italy

Background: Osteoporosis is a frequent complication of rheumatic muscle-skeletal diseases (RMD), with high impact from steroid treatment It is known that bDMARD impact positively on patients' prognosis and this is also known for Denosumab, a monoclonal antibody for osteoporosis. The combination treatment with two monoclonal antibodies, bDMARD \& denosumab, has addressed the problem of safety and efficacy, with incomplete answers from the available literature.

Objectives: to evaluate the impact of the combination treatment bDMARD +Denosumab (COMBO group), compared to mono-therapy with bDMARD (MONO group), on clinical efficacy, safety and treatment retention of bDMARD in patients with RMD. 